\title{
Characterization of a human Bid homologue protein from Gallus gallus
}

\author{
Gema Díaz-Gil ${ }^{\text {a,*}}$, Francisco Gómez-Esquer ${ }^{\text {a }}$, David Agudo ${ }^{\text {a }}$, José Delcán ${ }^{\text {a }}$, \\ Fernando Martínez-Arribas ${ }^{\mathrm{b}}$, Carmen Rivas ${ }^{\mathrm{c}}$, José Schneider ${ }^{\mathrm{b}}$, \\ $\mathrm{M}^{\mathrm{a}}$ Angustias Palomar ${ }^{\mathrm{a}}$, Rafael Linares ${ }^{\mathrm{a}}$ \\ a Departamento de Ciencias de la Salud III, Universidad Rey Juan Carlos, 28922, Alcorcón, Madrid, Spain \\ b Departamento de Ciencias de la Salud II, Universidad Rey Juan Carlos, 28922, Alcorcón, Madrid, Spain

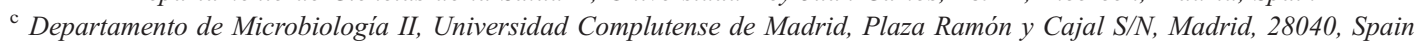

Received 6 May 2005; received in revised form 30 September 2005; accepted 15 December 2005

Available online 17 February 2006

\begin{abstract}
Bid protein, a member of the "BH3-only" subgroup of Bcl-2 family, plays a critical role in mammalian apoptosis regulation. In this study, we have cloned the chicken Bid gene, which encodes a 193 amino acid protein and shares $40 \%$ homology with human and mouse Bid proteins. Bid sequence comparison emphasises the conservation of both the functional domain $\mathrm{BH} 3$ and the proteolytic cleavage sites. An induction of apoptosis by chicken Bid and the cleavage of the protein, after TNF $\alpha$ treatment, were also demonstrated. In addition, mRNA Bid expression was detected along all embryo stages and tissues examined, suggesting a role for this protein in the developmental process. This is the first report demonstrating the functionality of a "BH3-only" protein in chicken.
\end{abstract}

(C) 2006 Elsevier B.V. All rights reserved.

Keywords: Chicken embryo; Programmed cell death; Bcl-2 family

\section{Introduction}

Apoptosis, also called programmed cell death, is critical during development and tissue homeostasis and plays a role in the pathogenesis of a variety of diseases (Strasser et al., 1990; Thompson, 1995; Bouillet et al., 1999). One important regulator of apoptosis is the Bcl-2 family of proteins that can be grouped into subfamilies of pro-survival and pro-apoptotic molecules (Petros et al., 2004). Members of this family are characterized by the presence of several conserved motifs, known as the Bcl-2 homology domains (BH1-BH4). Pro-apoptotic family members either share the multidomain structure (e.g. Bax and Bak) or contain only the BH3 domain (e.g. Bid, Bad, Bmf). The last proteins, termed collectively as the "BH3-only" molecules, have been suggested to play an important role in initiating

Abbreviations: cDNA, DNA complementary to RNA; CHX, Cycloheximide; GFP, Green fluorescent protein; RT-PCR, Reverse transcriptionpolymerase chain reaction.

* Corresponding author. Universidad Rey Juan Carlos, Facultad de Ciencias de la Salud, Departamento de Ciencias de la Salud III, Avenida de Atenas, S/N, E28922. Alcorcón, Madrid, Spain. Tel.: +34 914888 908; fax: +34 914888831.

E-mail address: gema.diaz@urjc.es (G. Díaz-Gil). mitochondrial-mediated apoptosis (Bouillet and Strasser, 2002). At least eight "BH3-only" proteins have been identified in mammals (Strasser, 2005), suggesting that they detect different stress conditions and are critical for programmed cell death in specific tissues. In contrast, in C. elegans, a single "BH3-only" protein, EGL-1, is required for the initiation of all developmentally programmed deaths (Conradt and Horvitz, 1998), suggesting that although conserved, these mechanisms are rather simple in invertebrates. From the complexity of the mammals to the simplicity of the invertebrates, other organisms exist in which apoptosis mechanisms are clearly conserved. Studies in these organisms together with evolutionary analysis, will contribute to discover or better understanding the function of the "BH3-only" members.

Gallus gallus has been considered one of the most important model organisms for studying vertebrate development and diseases (Richman et al., 2002; Sakar et al., 2004). In contrast with mouse embryos, the large and robust chick embryos are accessible during the stages when most important developmental decisions are taken so that a large variety of methodologies can be used to analyze the genetic regulation of many different developmental processes. In addition, a draft genome sequence 
of $G$. gallus has been recently published, providing a new perspective on vertebrate genome evolution (Hillier et al., 2004) and consolidating the chicken as an important model organism that bridges the evolutionary gap between mammals and others vertebrates. However, although apoptosis is an essential mechanism during development, few things are known about this pathway in chicken. Just a few Bcl-2 family members, sharing significant homology to mammalian apoptosis genes have been described in this organism (Eguchi et al., 1992; Boise et al., 1993; Lee et al., 1999), but not "BH3-only" proteins from chicken have been characterized so far. In the present study, we have cloned, expressed and characterized the "BH3-only" protein Bid from G. gallus. The developmental expression pattern and the ability to induce apoptosis of this Bcl-2 family protein were examined.

\section{Materials and methods}

\subsection{Chick embryos and incubation conditions}

Fertilized White Leghorn hens' eggs were incubated at $37.5^{\circ} \mathrm{C}$ and $70 \%$ relative humidity in an Octagon $40 \mathrm{DX}$ incubator (Brinsea Products Ltd, Sandford, UK), and the resulting embryos were staged as described previously (Hamburger and Hamilton, 1951). The embryos were dissected free of extraembryonic membranes, washed in phosphate buffered saline, rinsed in distilled water, immersed in RNAlater ${ }^{\mathrm{TM}}$ (Ambion Inc, Austin, Texas, USA) and, immediately, in liquid nitrogen and conserved at $-80{ }^{\circ} \mathrm{C}$ until further use.

\subsection{RNA isolation}

Total RNA was isolated from whole embryos and heart and liver tissues at different stages of development using the Protein And RNA Isolation System (PARISTM) according to the instructions of the manufacturer (Ambion).

\subsection{Synthesis of full length cDNA and plasmid construction}

The chicken Bid cDNA was generated using an RT-PCR cloning approach. Total RNA from embryos at different stages was reversely transcribed and amplified using the One Step RTPCR kit (Qiagen, Hilden, Germany) following the manufacturer's instructions. The primers were designed based on the chicken Bid sequence deposited in GenBank (GeneBank accession no. AY112660). The primers used were: GgBid-S, 5'-ATGGAACAGGATATCTACAG-3' and GgBid-AS, 5' TCAGTCCATCTCGTTTCTAA-3'. RT-PCR amplification was carried out in an iCycler ${ }^{\mathrm{TM}}$ thermal cycler (Bio-Rad, Hercules, CA, USA) using the following program: reverse transcription at $50{ }^{\circ} \mathrm{C}$ for $30 \mathrm{~min}$, initial PCR activation step at $95^{\circ} \mathrm{C}$ for $15 \mathrm{~min}, 35 \mathrm{PCR}$ amplification cycles at $94{ }^{\circ} \mathrm{C}$ for $30 \mathrm{~s}$, $50{ }^{\circ} \mathrm{C}$ for $30 \mathrm{~s}, 72{ }^{\circ} \mathrm{C}$ for $30 \mathrm{~s}$ and a final extension cycle of $72{ }^{\circ} \mathrm{C}$ for $10 \mathrm{~min}$. The PCR product was cloned directly into the pGEM-T easy vector (Promega, Madison, WI, USA) and sequenced in both directions using the PRISM Ready Reaction Dye Deoxy Termination Cycle sequencing Kit (Applied
Biosystems, CA, USA) on an Applied Biosystems 3100Avant automated DNA sequencer. A plasmid designed to express G. gallus Bid was constructed by cloning the coding region into the pEGFP-N1 expression vector (Clontech, CA, USA). The primers designed for this purpose were: Bidc-S, 5'CGCGGAATTCCAAATGGAACAGGATATC-3' and BidcAS, 5'-CGCGGGATCCCGCTCACGCAGCATTCT-3' (EcoRI and $B a m \mathrm{HI}$ restriction sites are indicated in cursive text). The PCR product was EcoRI/BamHI digested and fused to an EcoRI/BamHI digested pEGFP-N1 vector to generate the expression plasmid pEGFP-N1-Bid. The orientation and the sequence were confirmed by sequencing the entire insert.

\subsection{Cell culture, transfection and induction of apoptosis}

MCF7 cells were maintained in Dulbecco's modified medium supplemented with $10 \%$ fetal bovine serum, $2 \mathrm{mM}$ L-glutamine and $1 \%$ antibiotics. Cells were transfected with the empty vector pEGFP-N1 or the expression plasmid pEGFP-N1Bid by using CytoPure ${ }^{\mathrm{TM}}$ Transfection Reagent (Qbiogen Inc, $\mathrm{CA}$ ), according to the manufacturer's instructions. $24 \mathrm{~h}$ after transfection $10 \mathrm{ng} / \mathrm{ml} \mathrm{TNF} \alpha$ (Biosource International) and $1 \mu \mathrm{g} / \mathrm{ml} \mathrm{CHX} \mathrm{(Sigma)} \mathrm{were} \mathrm{added} \mathrm{to} \mathrm{the} \mathrm{medium} \mathrm{and} 4 \mathrm{~h}$ later determination of apoptosis was carried out.

\subsection{Apoptosis analysis}

Typical apoptotic morphology includes cellular shrinkage and the formation of apoptotic bodies. Morphology of transfected cells was examined with an Eclipse TE2000U microscope (Nikon). Apoptosis was also analyzed by surface staining with the APC-conjugated recombinant annexin V (Bender MedSystems GmbH, Campus Vienna Biocenter 2, Vienna, Austria) according to the manufacturer's instructions. The stained cells were analyzed by flow cytometry using a CYAN (DAKO Cytomation), and data were analyzed by using Summit software (DAKO Cytomation). The experiments were repeated for at least four times with duplicate dishes for each condition in every experiment.

\subsection{RT-PCR analysis}

Semi-quantitative RT-PCR analysis of chicken Bid expression was performed using the above mentioned primers: GgBid$\mathrm{S}$ and GgBid-AS. The synthesis of cDNA from different chicken stages and organs was carried out as described above for the cloning procedure. As internal control gene, chicken $\beta$-actin was detected using a set of gene-specific $\beta$-actin primers, generating a DNA fragment of $298 \mathrm{bp}$. The primers used were: Actin-S, 5'-GATGACACAGATCATGTTTG-3' and Actin-AS, 5'-GCACAGCTTCTCCTTGATG-3'. The primers' concentration of the target and the internal control gene was adjusted to 0.6 and $0.3 \mu \mathrm{M}$, respectively, so that the final band densities were similar and both reactions were within the ascending slope of the respective saturation curves using the same number of extension cycles (35 cycles). The samples were resolved on a $2 \%$ agarose gel with $1 \mu \mathrm{g} / \mathrm{ml}$ of ethidium bromide 
and analyzed in a UV-Transilluminator mini darkroom ${ }^{\mathrm{TM}}$ (UVP, Upland, CA) using the Labworks Analysis Sotfware ${ }^{\mathrm{TM}}$ (UVP).

\subsection{Western blot analysis}

Cells transfected with the pEGFP-N1-Bid expression plasmid and incubated or not with the caspase 8 inhibitor II (Calbiochem) were treated with $\mathrm{TNF} \alpha$ and $\mathrm{CHX}$ or CHX only as above described and $4 \mathrm{~h}$ after treatment cells lysates were prepared in lysis buffer $(20 \mathrm{mM}$ Tris, $150 \mathrm{mM} \mathrm{NaCl}, 1 \mathrm{mM}$ $\mathrm{MgCl}_{2}, 1 \%$ Nonidet P-40 (NP-40), 10\% glycerol, $1 \mathrm{mM}$ dithiothreitol (DTT), $50 \mathrm{mM} \beta$-glycerophosphate, $50 \mathrm{mM} \mathrm{NaF}$, $10 \mu \mathrm{g} / \mathrm{ml}$ phenymethylsulfonyl fluoride, $4 \mu \mathrm{g} / \mathrm{ml}$ aprotinin, $4 \mu \mathrm{g} / \mathrm{ml}$ leupeptin, and $4 \mu \mathrm{g} / \mathrm{ml}$ pepstatin [pH 7.4]). Lysates were then cleared by centrifugation and $100 \mu \mathrm{g}$ of proteins were resolved by SDS-PAGE electrophoresis and transferred on to

A

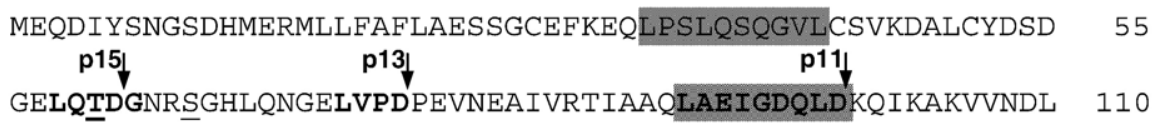

VQHFLNENLPREEITRCLSQAVEGLARAIPSDLEQEKAMLVLAMLLTKKVANQMP 165

$\begin{array}{ll}\text { SLLQRVFSTTVNYISQHFHNYIVRMLRE } & 193\end{array}$

B

MmBid

RnBid

HsBid

GgBid

MmBid

RnBid

HsBid

GgBid

MmBid

RnBid

HsBid

GgBid

MmBid

RnBid

HsBid

GgBid

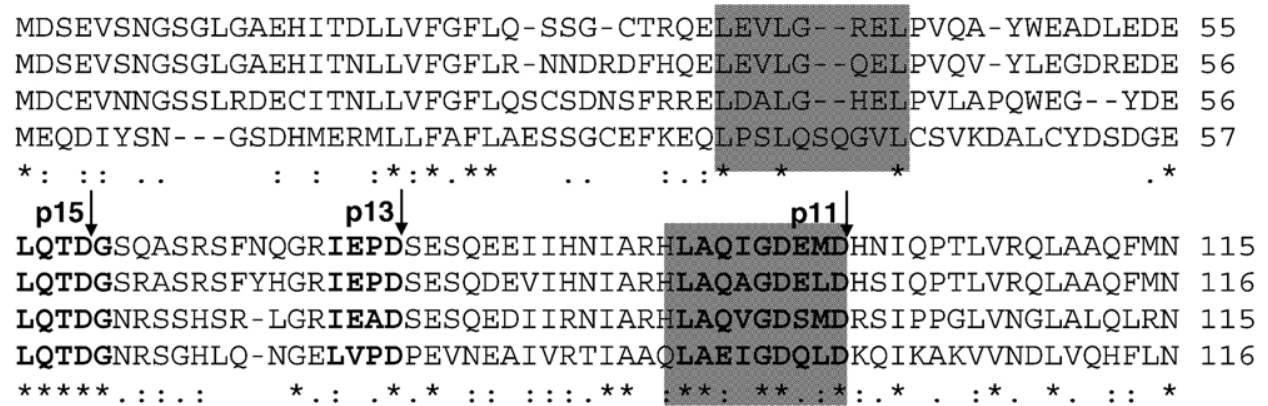

GSLSEEDKRNCLAKALDEVKTAFPRDMENDKAMLIMTMLLAKKVASHAPSLLRDVFHTTV 175 GSLSEEDKRNCLAKALDEVKTSFPRDMENDKAMLIMTMLLAKKVASHAPSLLRDVFRTTV 176 TSRSEEDRNRDLATALEQLLQAYPRDMEKEKTMLVLALLLAKKVASHTPSLLRDVFHTTV 175 ENLPREEITRCLSQAVEGLARAI PSDLEQEKAMLVLAMLLTKKVANQMPSLLQRVFSTTV 176

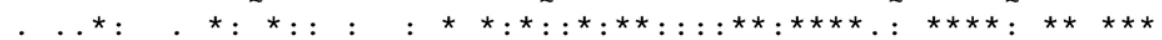

NFINQNLFSYVRNLVRNEMD 195

NFINQNLFSYVRDLVRNEMD 196

NFINQNLRTYVRSLARNGMD 195

NYISQHFHNYIVRMLRE-- - 193

* : * * : . * : : * :

$\%$ Identity to GgBid

\begin{tabular}{cccccc} 
& & & \multirow{2}{c}{ BH3-B } & \multicolumn{2}{c}{ Proteolityc cleavage sites } \\
Homologue & ORF & BH3 domain & $\begin{array}{c}\text { domain } \\
\text { 57-62 aa }\end{array}$ & $\mathbf{7 3 - 7 6}$ aa \\
\hline HsBid & 40 & 55 & 28 & 100 & 25 \\
MmBid & 41 & 66 & 28 & 100 & 50 \\
RnBid & 37 & 66 & 28 & 100 & 50 \\
\hline
\end{tabular}

Fig. 1. Sequence analysis of Gallus gallus Bid protein. (A) Amino acid sequence of chicken Bid protein. The BH3 (residues 91-99) and BH3-like (residues 34-43) domains are shown with boxes in dark and light grey, respectively. Boldface indicates putative cleavage sites, generating p15 (15 kDa), p13 (13 kDa) and p11 (11 kDa) truncated Bid forms. Possible phosphorylation sites are underlined. (B) Sequence alignment of chicken (Gg) (GeneBank accession no. AY112660), human (Hs) (GeneBank accession no. P55957), mouse (Mm) (GeneBank accession no. P70444) and rat (Rn) (GeneBank accession no. NM_022684) Bid proteins. Identical amino acids are denoted by *, and - or : denotes similar amino acids. The BH3 and BH3-like (BH3-B) domains are indicated by dark and light grey boxes, respectively. The cleavage sites are indicated in boldface, showing by arrows the truncated Bid forms generated by this cleavage. The (\%) identity was obtained from Clustal protein alignment. ORF indicates Open Reading Frame. 
nitrocellulose membrane. Western blot was done using antiGFP antibody.

\subsection{Bioinformatics}

Nucleotide sequence and protein similarity analyses were carried out using Chromas v2.21 (http://www.technelysium. com.au/chromas.html) and BLAST programs (http://www.ncbi. nlm.nih.gov/BLAST/), respectively. Alignment of amino acid sequences was constructed using the ClustalW method, based on amino acid similarities of the full sequences (http://www.ebi. ac.uk/clustalw/) (Thompson et al., 1994). Phylogenetic and molecular evolutionary analyses were conducted using Molecular Evolutionary Genetics Analysis (MEGA, version 3.0; http://www.megasoftware.net/mega.html) (Kumar et al., 2004). One thousand bootstrap trials were run using the neighbourjoining algorithm.

\section{Results and discussion}

\subsection{Characterization of $G$. gallus Bid sequence and comparison among species}

On the basis of the information from Bid cDNA deposited in GeneBank we performed a RT-PCR and obtained the complete sequence of $G$. gallus Bid. The cDNA sequence of chicken contains an ORF of 582 bp which encodes for a protein of 193 amino acids. The protein shows a $\mathrm{BH} 3$ domain (amino acid residues 91 to 99) and a putative $\mathrm{BH} 3$-like domain (amino acid residues 34 to 43 ) (Fig. 1A). It has been shown that an intact $\mathrm{BH} 3$ domain is required for " $\mathrm{BH} 3$-only" proteins to dimerize with Bcl-2 family members and trigger apoptosis when overexpressed (Huang and Strasser, 2000). On the other hand, the pro-apoptotic potential of $\mathrm{Bid}$ has been proposed to be negatively regulated by an autoinhibitory mechanism involving intermolecular interaction of the $\mathrm{BH} 3$-like and $\mathrm{BH} 3$ domain (Tan et al., 1999). The cleavage by caspase 8 and granzyme B, in human Bid, generates truncated forms of the Bid protein (tBid) of $15 \mathrm{kDa}(\mathrm{p} 15)$ and $13 \mathrm{kDa}(\mathrm{p} 13)$, respectively. In healthy cells the Bid protein remains in the cytosol and different apoptotic signals induce its cleavage and the translocation of the truncated proteins to the mitochondria, where they promote the exit of cytochrome $c$ (Gross et al., 1999). In the G. gallus Bid sequence, hypothetical cleavage sites for caspases, granzyme B and various lysosomal proteases are also found. The cleavage site for caspase 8 would be located between 57 and 62 amino acid residues, and the cleavage site for granzyme B at 73 to 76 residues (Fig. 1A). Another putative cleavage site is found at the 99 amino acid residue in the chicken sequence, obtaining a $11 \mathrm{kDa}$ protein $(\mathrm{p} 11)$. As in mammals, the p11 Bid fragment lacks the $\mathrm{BH} 3$ domain, which should result in an inactive protein (Gross et al., 1999). Desagher et al. (2001) described that after the phosphorylation of Bid by casein kinase I and II, the protein is insensitive to caspase 8 cleavage. Possible phosphorylation sites, regulating caspase 8 cleavage are also found at T60 and S65 residues of chicken Bid (Fig. 1A).

The similarity between the amino acid sequence of the chicken Bid and several reported mammalian Bid proteins was then determined by the ClustalW method (Thompson et al., 1994). Sequence comparison between chicken and human Bid shows $40 \%$ identity, similar to the comparison between chicken and mouse $(41 \%)$ or rat $(37 \%)$. The multiple alignments of Bid amino acid sequences (Fig. 1B) reveal several regions which are highly conserved. The highest identity is found in the caspase 8 cleavage site $(100 \%)$, whereas the chicken granzyme B cleavage site is less closely related to mammalian sequences (Fig. 1B). Recently it has been described that the cleavage site for granzyme B, outside of mammals, appears to be poorly conserved, perhaps indicating that the processing by this enzyme is not critical for Bid (Coultas et al., 2002). The chicken $\mathrm{BH} 3$ domain shares 55\% homology with the human domain and $66 \%$ with mouse and rat proteins. The highly conserved amino acid residues leucine, glycine and aspartate in the BH3 domain are present in all the sequences, consistent with the involvement of this region in functional activity (Bouillet and Strasser, 2002). Less similarity is detected at the BH3-like domain where the chicken sequence shows the lowest homology (Fig. 1B).

In an effort to determine the evolutionary relationship between members of Bid proteins, a phylogenetic tree was

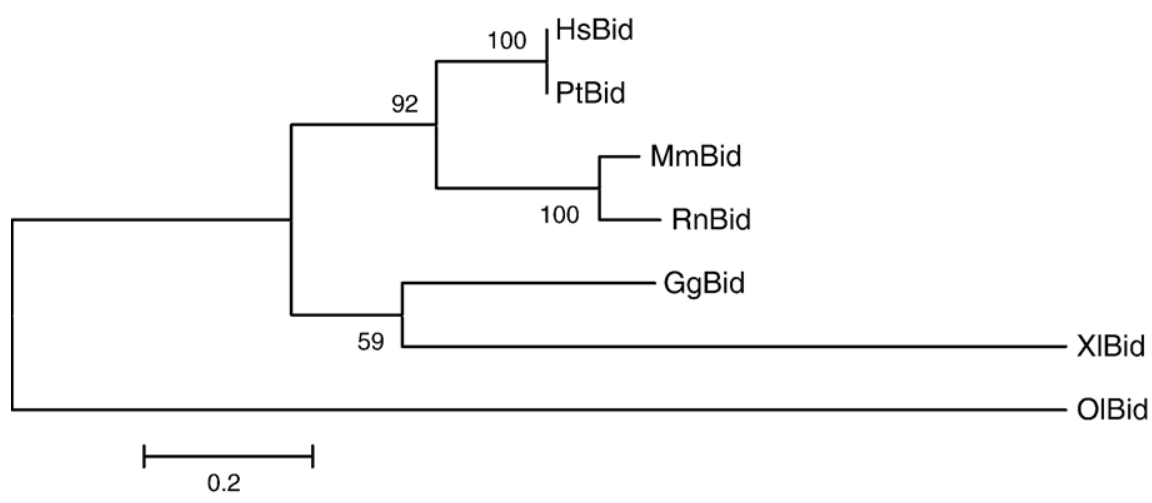

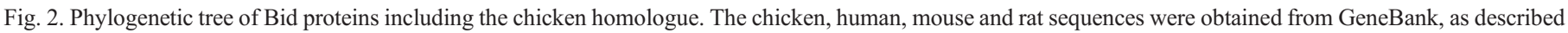

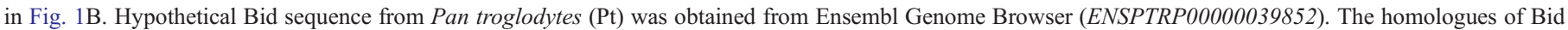

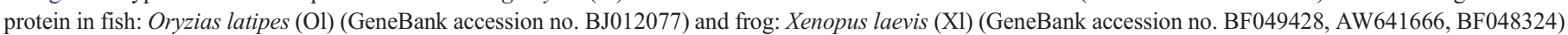
were identified by Coultas et al. (2002). 
constructed using MEGA. Seven different Bid proteins were used for the analysis (Fig. 2). As the evolutionary tree shows, Bid proteins are separated into different clades reflecting their evolution. The human and the chimpanzee Bid proteins, not surprisingly, are sisters in their own clade. Similarly, the two rodent sequences form a separate clade. The chicken Bid appears to form the same clade together with frog (X. laevis) species, although they are not very close in their evolutionary relationship. Moreover, Bid fish (O. latipes) appears to form an outgroup in the phylogenetic tree. Interestingly, we observed that the chicken clade seems to evolve from a common origin with hominid and rodent clades. Recently, a phylogenetic analysis of the Bcl-2 family has been presented by Lanave et al. (2004), including three Bcl-2 members identified in chicken (Bcl-2, Nr13 and Bok). In agreement with our results, this study revealed that chicken $\mathrm{Bcl}-2$ members were closely related to mammals whereas other vertebrates like zebrafish appear to be wide apart. This indicates that the chicken as a vertebrate model is a valuable genetic tool to examine the roles of "BH3-only" proteins in both development and disease.

\subsection{G. gallus Bid is cleaved in vivo during TNF $\alpha$-induced apoptosis and its activity depends upon its cleavage}

Transfection of the cells with the pEGFP-N1-Bid expression plasmid indicated that the subcellular localization of the chicken Bid was similar to that reported for other Bid proteins (Wang et al., 1996), i.e., it was distributed in both cytosol and membrane (Fig. 3A). In addition, transfection of the cells with the control vector (pEGFP-N1) or pEGFP-N1-Bid construction did not show significant levels of apoptosis. However, after treatment of the cells with TNF $\alpha$ and CHX, cells transfected with pEGFPN1-Bid construction underwent typical apoptotic changes such as rounding, membrane blebbing and detachment from the dish (Fig. 3A). These results were also confirmed using annexin $\mathrm{V}$ assay (Fig. 3B).

In order to examine if there was a correlation between the induction of apoptosis and the cleavage of the chicken Bid, we transfected C-terminal GFP-tagged chicken Bid into MCF7 cells and treated with TNF $\alpha$ and CHX to induce the activation of caspase 8 and a Western blot of the cell lysates
A

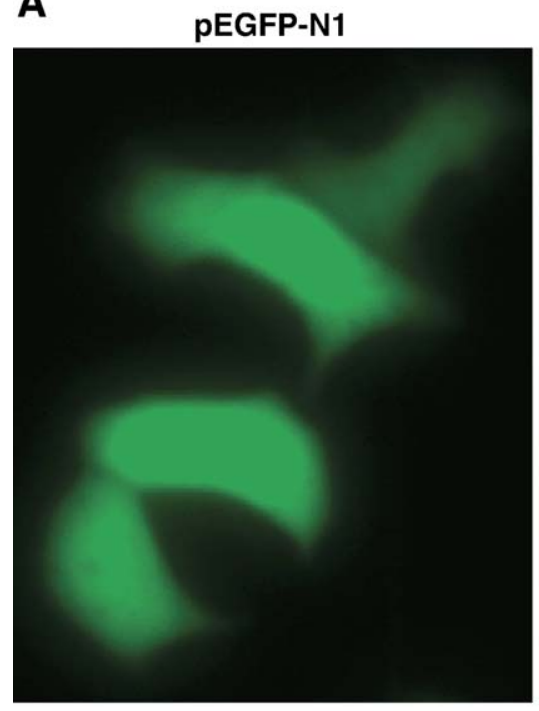

B

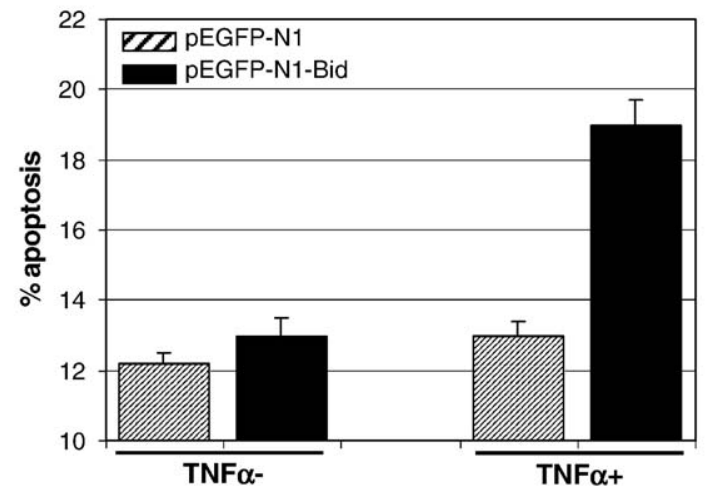

pEGFP-N1-Bid/ TNF $\alpha-$

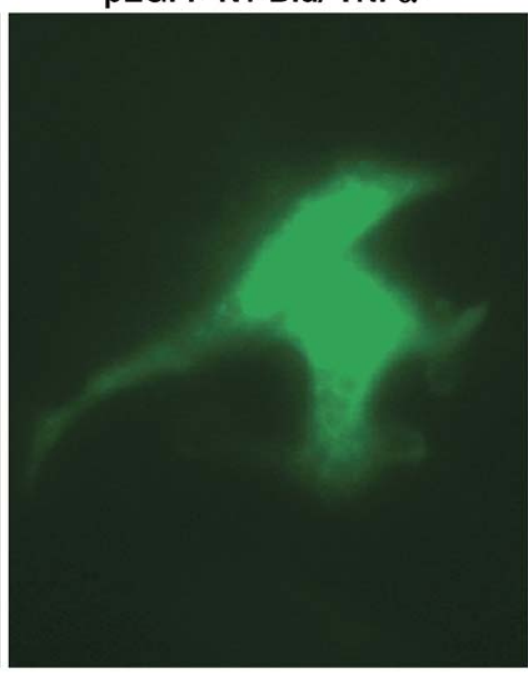

C

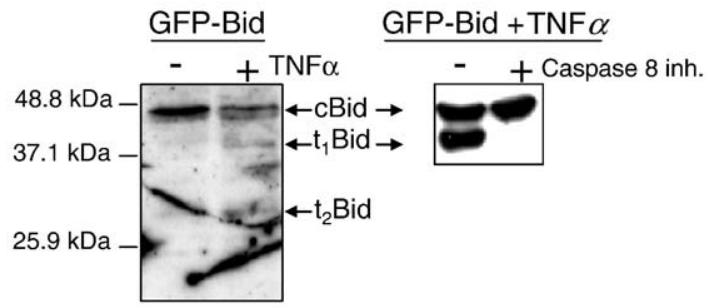

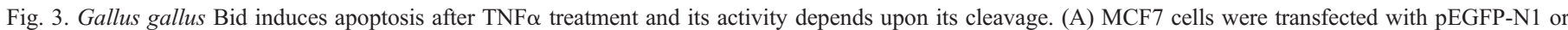

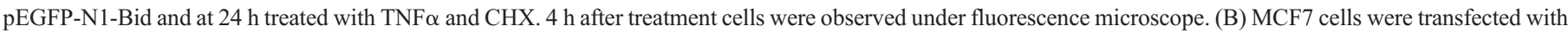

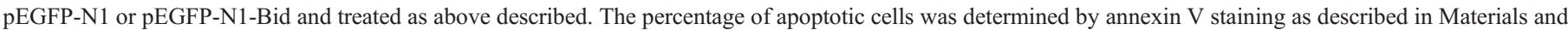

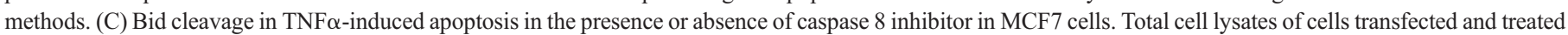
as above described were prepared and blotted with anti-GFP antibody. Arrows point the full length Bid (cBid) and the two cleavage products, $\mathrm{t}_{1} \mathrm{Bid}$ and $\mathrm{t}_{2} \mathrm{Bid}$. 

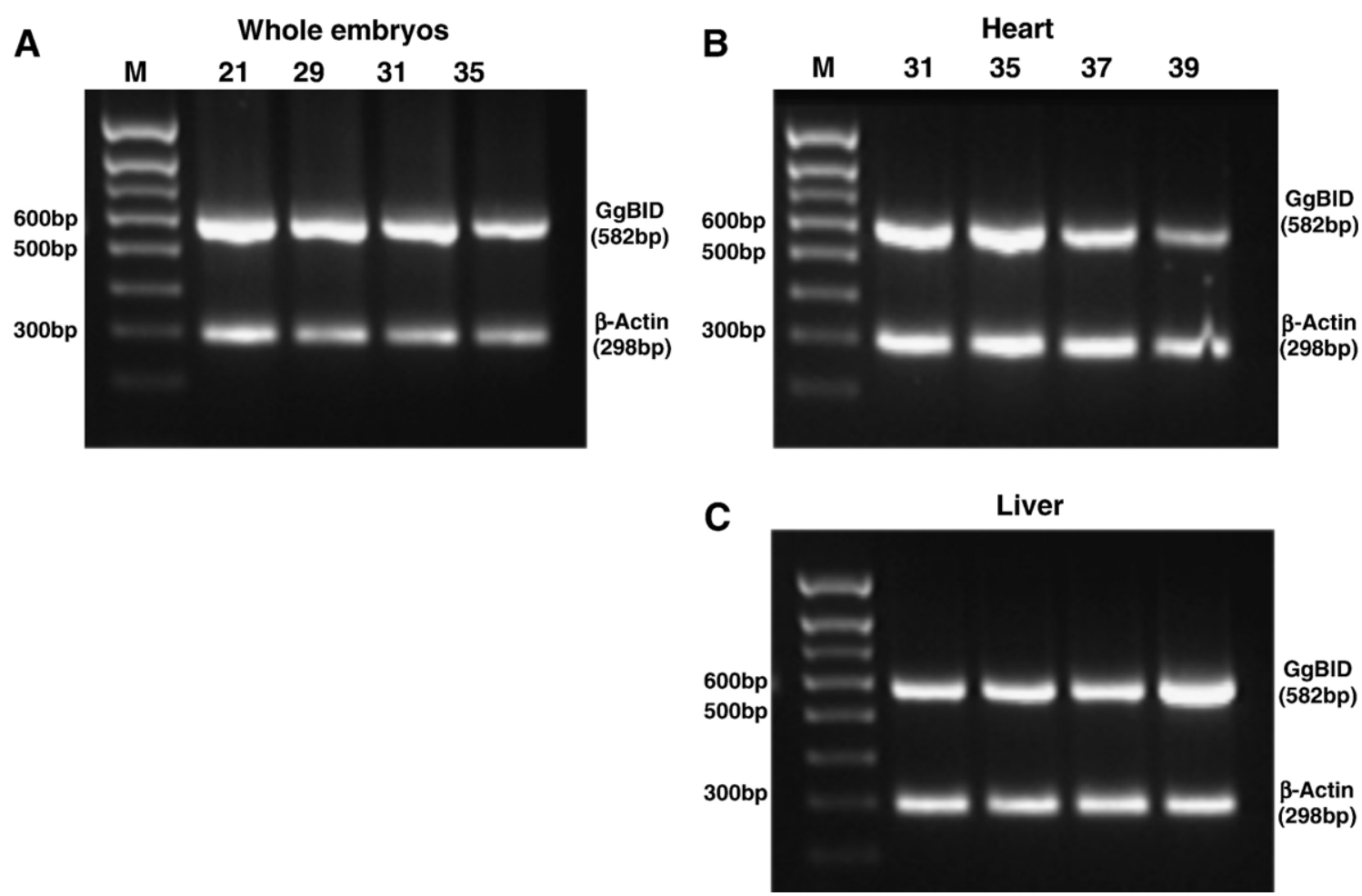

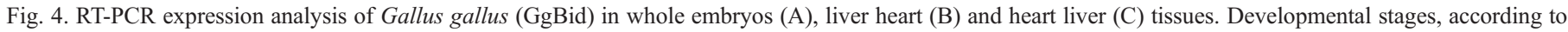
Hamburger and Hamilton, are indicated. Expression profiles of chicken Bid cDNA and chicken $\beta$-actin are shown. DNA size markers (M) are indicated in bp.

was then carried out using anti-GFP antibody. As shown in Fig. 3C, only when MCF7 cells were treated with TNF $\alpha$ and CHX treatment, the full length Bid (cBid) was cleaved and the $t_{1}$ Bid and $t_{2}$ Bid fragments were detected. In addition, the molecular size of $\mathrm{t}_{1} \mathrm{Bid}$ was about $15 \mathrm{kDa}$ that was in agreement with the molecular size after hypothetic cleavage by caspase 8 in G. gallus Bid protein. In order to demonstrate that the cleavage of the Bid protein is caused after caspase 8 activation, we performed an experiment where apoptosis in MCF7 cells was induced as previously described, but in the presence or absence of caspase 8 inhibitor. The generation of tBid fragments was not detected when the caspase 8 inhibitor was present (see Fig. 3C).

These results show for the first time the functionality of a "BH3-only" protein from chicken, and reveal that, as in human or mouse, the full length chicken Bid, without apoptotic stimuli, has relatively poor pro-apoptotic activity. Nevertheless this activity is greatly augmented after death-receptor-induced apoptosis, which produced tBid (truncated Bid) after caspase 8 proteolysis (Strasser, 2005).

\subsection{Bid expression analysis in whole chicken embryos and tissues at different stages of development}

In order to determine the expression pattern of G. gallus Bid mRNA, whole chicken embryos at different developmental stages and various tissues from these embryos were analyzed using semi-quantitative RT-PCR analysis. We only detected the expected $582 \mathrm{bp}$ transcript, whereas three isoforms of Bid protein, generated by alternative splicing, have been described in humans (Renshaw et al., 2004). As illustrated in Fig. 4, our data showed that the chicken Bid mRNA was detected in the whole embryos analyzed at the different development stages, as well as in liver and heart tissues, suggesting a role for this protein in the regulation of several tissue development. However, further studies are required to elucidate the importance of Bid protein in chicken embryogenesis.

\section{Conclusions}

This study reports for the first time the cloning and characterization of a "BH3-only" protein in chicken. TNF $\alpha$ treatment of cells expressing chicken Bid rapidly induced apoptosis in MCF7 cells, demonstrating the functionality of this protein. Moreover, G. gallus Bid shares all the main characteristics of its Bid mammalian homologues, providing a valuable tool to understand the role of the "BH3-only" proteins in developmental processes.

\section{Acknowledgements}

We thank Beatriz Santamaría from Universidad Rey Juan Carlos for optimal technical assistance. We also thank José Antonio Mas Gutiérrez at Unidad de Genómica (Centro de Apoyo Tecnológico) from Universidad Rey Juan Carlos for his help in DNA sequencing. This work was supported by PPR-2004-18 from the Programa Propio de Fomento de la Investigación of the Universidad Rey Juan Carlos and FIS PI020432 from the Fondo de Investigación Sanitaria. 


\section{References}

Boise, L.H., et al., 1993. Bcl-x, a bcl-2-related gene that functions as a dominant regulator of apoptotic cell death. Cell 74, 597-608.

Bouillet, P., Strasser, A., 2002. BH3-only proteins - evolutionarily conserved proapoptotic Bcl-2 family members essential for initiating programmed cell death. J. Cell Sci. 115, 1567-1574.

Bouillet, P., et al., 1999. Proapoptotic Bcl-2 relative Bim required for certain apoptotic responses, leukocyte homeostasis, and to preclude autoimmunity. Science 286, 1735-1738.

Conradt, B., Horvitz, H.R., 1998. The C. elegans protein EGL-1 is required for programmed cell death and interacts with the Bcl-2-like protein CED-9. Cell 93, 519-529.

Coultas, L., Huang, D.C., Adams, J.M., Strasser, A., 2002. Pro-apoptotic BH3only Bcl-2 family members in vertebrate model organisms suitable for genetic experimentation. Cell Death Differ. 9, 1163-1166.

Desagher, S., et al., 2001. Phosphorylation of bid by casein kinases I and II regulates its cleavage by caspase 8 . Mol. Cell 8, 601-611.

Eguchi, Y., Ewert, D.L., Tsujimoto, Y., 1992. Isolation and characterization of the chicken bcl-2 gene: expression in a variety of tissues including lymphoid and neuronal organs in adult and embryo. Nucleic Acids Res. 20, 4187-4192.

Gross, A., et al., 1999. Caspase cleaved BID targets mitochondria and is required for cytochrome $c$ release, while BCL-XL prevents this release but not tumor necrosis factor-R1/Fas death. J. Biol. Chem. 274, 1156-1163.

Hamburger, V., Hamilton, H.L., 1951. A series of normal stages in the development of the chick embryo. Dev. Dyn. 195, 231-272.

Hillier, et al., 2004. Sequence and comparative analysis of the chicken genome provide unique perspectives on vertebrate evolution. Nature 432, 695-716.

Huang, D.C., Strasser, A., 2000. BH3-only proteins - essential initiators of apoptotic cell death. Cell 103, 839-842.

Kumar, S., Tamura, K., Nei, M., 2004. MEGA3: integrated software for Molecular Evolutionary Genetics Analysis and sequence alignment. Brief Bioinform. 5, 150-163.
Lanave, C., Santamaria, M., Saccone, C., 2004. Comparative genomics: the evolutionary history of the Bcl-2 family. Gene 333, 71-79.

Lee, R.M., Gillet, G., Burnside, J., Thomas, S.J., Neiman, P., 1999. Role of Nr13 in regulation of programmed cell death in the bursa of Fabricius. Genes Dev. $13,718-728$.

Petros, A.M., Olejniczak, E.T., Fesik, S.W., 2004. Structural biology of the Bcl-2 family of proteins. Biochim. Biophys. Acta 1644, 83-94.

Renshaw, S.A., et al., 2004. Three novel Bid proteins generated by alternative splicing of the human Bid gene. J. Biol. Chem. 279, 2846-2855.

Richman, J.M., Fu, K.K., Cox, L.L., Sibbons, J.P., Cox, T.C., 2002. Isolation and characterisation of the chick orthologue of the Opitz syndrome gene, Mid1, supports a conserved role in vertebrate development. Int. J. Dev. Biol. 46, 441-448.

Sakar, D., et al., 2004. Marek's disease vaccination, with turkey herpesvirus, and enrofloxacin modulate the activities of hepatic microsomal enzymes in broiler chickens. Acta Vet. Hung. 52, 211-217.

Strasser, A., 2005. The role of BH3-only proteins in the immune system. Nat. Rev. Immunol. 5, 189-200.

Strasser, A., Harris, A.W., Bath, M.L., Cory, S., 1990. Novel primitive lymphoid tumours induced in transgenic mice by cooperation between myc and bcl-2. Nature 348, 331-333.

Tan, K.O., Tan, K.M., Yu, V.C., 1999. A novel BH3-like domain in BID is required for intramolecular interaction and autoinhibition of pro-apoptotic activity. J. Biol. Chem. 274, 23687-23690.

Thompson, C.B., 1995. Apoptosis in the pathogenesis and treatment of disease. Science 267, 1456-1462.

Thompson, J.D., Higgins, D.G., Gibson, T.J., 1994. CLUSTAL W: improving the sensitivity of progressive multiple sequence alignment through sequence weighting, position-specific gap penalties and weight matrix choice. Nucleic Acids Res. 22, 4673-4680.

Wang, K., Yin, X.M., Chao, D.T., Milliman, C.L., Korsmeyer, S.J., 1996. BID: a novel BH3 domain-only death agonist. Genes Dev. 10, 2859-2869. 